http://jmscr.igmpublication.org/home/ ISSN (e)-2347-176x ISSN (p) 2455-0450

crossref DOI: https://dx.doi.org/10.18535/jmscr/v8i2.118

\title{
Prophylactic Intravenous Ephedrine to Prevent Spinal Induced Hypotension during Cesarean Section- A Comparative Study
}

\author{
Authors \\ Bimal Krushna Panda ${ }^{1}$, Saransh Mishra², Pankaj Verma ${ }^{3}$, \\ Diptimayee Pradhan ${ }^{4}$, Sarita Patnaik ${ }^{5}$, Ratikanta Nayak ${ }^{6}$ \\ ${ }^{1}$ Associate Professor, Department of Anaesthesiology, VIMSAR, Burla, Odisha \\ ${ }^{2}$ Junior Resident, Department of Anaesthesiology, VIMSAR, Burla, Odisha \\ ${ }^{3,4}$ Assistant Professor, Department of Anaesthesiology, VIMSAR, Burla, Odisha \\ ${ }^{5}$ Junior Resident, Department of Anaesthesiology, VIMSAR, Burla, Odisha \\ ${ }^{6}$ Ratikanta Nayak, Senior Resident, Department of Anaesthesiology, MKCG Medical College, \\ Berhampur, Odisha
}

\begin{abstract}
Background and Aim: Spinal anesthesia is the most common preferred technique for cesarean delivery. Spinal anesthesia provides a fast, profound and symmetrical sensory and motor blockade of high quality in patients undergoing LSCS. However, the most common serious adverse effect of spinal anesthesia for LSCS is hypotension which has detrimental effects on uterine blood flow causing fetal hypoxia and acidosis. Preloading with crystalloids and use of vasopressors is widely recommended to prevent hypotension. The study has been undertaken to determine the effect of bolus intravenous ephedrine to be administered to LSCS patients to avoid spinal induced hypotension and to observe the hemodynamic response and the incidence of various side effects to prophylactic bolus dose of intravenous ephedrine.

Materials and Methods: A prospective experimental RCT was conducted with 60 parturients of 18-45 years, scheduled for cesarean section under spinal anaesthesia belonging to ASA Grade I and Grade II fulfilling the inclusion criteria, who were randomly allocated into 2 groups of 30 patients each: Group 1 (Ephedrine 10mg) and Group 2 (Normal saline-control), to be administered intravenously, just after spinal anesthesia.

Results: The incidence of hypotension was $20 \%$ and $46.66 \%$ in Group-1 and 2, respectively ( $p=0.008$ ). The occurrence of incidence of hypotension was sooner after spinal anesthesia as well as significantly higher in Group 2 in comparison to Group-1 patients. APGAR score was 9, 9 and 10 respectively at Omin, 1 min and 5mins in both the study groups. There is no incidence of nausea in Group-1 whereas it was $6.66 \%$ in Group-2 and incidence of vomiting was 6.66\% in Group-1 and 30\% in Group-2 and that of reactive hypertension was similar among both the groups.

Conclusion: Prophylactic use of intravenous ephedrine significantly decreased the incidence of maternal hypotension without unwanted side effects such as nausea, vomiting and hypertension and improved neonatal outcome as compared to equal volume of normal saline in women posted for elective LSCS and can be of great value in routine practice.

Keywords: Cesarean section, hypotension, intravenous bolus ephedrine, spinal anaesthesia.
\end{abstract}




\section{Introduction}

Spinal anaesthesia is frequently used for lower abdominal and lower extremity surgeries. It is simple to perform and is economical requiring comparatively less time than epidural anaesthesia to produce more rapid onset of good quality sensory and motor blockade. It is induced by injecting small amounts of local anaesthetic into cerebrospinal fluid (CSF) at either L2-3, L3-4, L4-5 interspinal levels.

It exposes the fetus to fewer drugs than general anaesthesia, while the mother can be awake when her baby is delivered. It has been shown to block the stress response to surgery, decreases intraoperative blood loss, lower the incidence of postoperative thromboembolism and decrease morbidity and mortality in high risk patients. ${ }^{[1]}$

Maternal hypotension is a recognized complication of spinal anaesthesia with an incidence of as high as $80 \%$, that may compromise the welfare of both mother and the baby. It is associated with distressing symptoms of dizziness, nausea and vomiting, and may also interfere with surgical procedure. If uncorrected, the decreased uterine blood flow may result in an acidotic neonate requiring active resuscitation. Reduced systemic vascular resistance causes hypotension, exacerbated in the parturient by inferior vena cava compression, which is partially compensated by increased stroke volume and heart rate. Lateral uterine displacement and preloading with crystalloids or colloids, physical methods such as leg bindings and compression stockings have been commonly used to prevent spinal-induced hypotension, but these alone may offer only a partial protection. A combination of preloading and vasopressor drugs has maximum efficacy in preventing spinal-induced hypotension. $^{[1]}$ Preloading with large doses of crystalloids and colloids may not be effective expanders of plasma volume, since $75 \%$ of the infused crystalloid volume rapidly diffuses into interstitial space and hence the effect is only transient. Pre-loading with large doses of crystalloid may result in an elevated central venous pressure, pulmonary edema and fetal hypooxygenation.

Ephedrine is an alkaloid with potent $\alpha$ and $\beta$ agonist and acts both by direct as well as indirect mechanism. $^{[2]}$ Ephedrine is proven to be more effective for increasing arterial blood pressure with better preservation of utero-placental blood flow as compared to other vasopressors. It has a predominant $\beta$-effect that causes increase in arterial blood pressure by increasing cardiac output rather than by vasoconstriction. ${ }^{[1]}$ The proposed significance of this study is that if it proves that the administration of ephedrine is beneficial in spinal anesthesia, then it will enable us to prevent significant hypotension as well as to avoid unnecessary delay in waiting for preloading with fluids. The incidence of hypotension, nausea and vomiting, reactive hypertension, bradycardia, tachycardia and APGAR scores are assessed during the study ${ }^{[2]}$.

In this study, we compared hemodynamic changes with $10 \mathrm{mg}$ bolus doses of prophylactic ephedrine and equal volume of normal saline. Hence, the present study is planned to study the effect of intravenous bolus ephedrine in ameliorating hypotension in cesarean delivery following intrathecal bupivacaine injection. ${ }^{[2]}$

Since there is no autoregulation for the placental vascular bed, prolonged maternal hypotension can be detrimental to the fetus, induce lower fetal Apgar scores, fetal acidosis and hypoxia. Therefore, in the present study, the researchers' attention was concentrated on pregnant women receiving SA, specialized subgroup of patients with the potential risk of uterine hypoperfusion and adverse neonatal outcomes. $^{[3]}$

\section{Methodology}

A double blind, randomized, interventional study was conducted under Department of Anesthesiology \& Intensive Care, VIMSAR, Burla. After obtaining hospital ethical committee approval and informed consent from patients, 60 parturients aged 18-45 years of ASA grade I and II, scheduled to receive spinal anesthesia for elective $\mathrm{C}$-section 
were randomly allocated two groups using a random number table. Group-1 received 10mg bolus dose of prophylactic ephedrine IV and Group- 2 received equal volume of $0.9 \%$ normal saline after administration of spinal anesthesia. Parturients with gestational age <37weeks, high risk pregnancy with medical complications like valvular heart disease, renal, metabolic disorders, pulmonary diseases, coagulation disorders or diabetes mellitus, obstetric complications like preeclampsia or pre-existing hypertension, any antenatal evidence of fetal anomalies, ASA physical status III and IV or any other contraindication of spinal anesthesia were excluded from groups.

All patients underwent pre anaesthetic examination and were fasted for 8 hours pre-operatively. An 18gauge intravenous cannula was inserted into their forearm. They were premedicated with Inj. Ranitidine 150mg IV and Inj. Ondensetron 4mg IV. On the operation table, standard monitoring of baseline heart rate, noninvasive $\mathrm{BP}$, pulse oximetry and ECG were done. The mean value of the first two consecutive measurements (with a $10 \mathrm{~min}$ interval after connecting the monitoring unit to the patient) was defined as the baseline blood pressure. Mean arterial blood pressure (MAP) was recorded. Every patient was preloaded with 500ml Ringer's solution over 15-20mins. Under all available aseptic precautions, spinal anaesthesia was given by making the patients to lie in left lateral position and then by injecting $10 \mathrm{mg}$ hyperbaric Inj. Bupivacaine $0.5 \%$ at level of L3-4 interspace, by using $25 \mathrm{G}$ Quincke's spinal needles in lateral bevel direction and at a rate of $0.2 \mathrm{ml}$ per second. Bolus dose of prophylactic study medication was randomly administered IV immediately on turning the patient to supine position from a prefilled syringe and the control group was administered equal volume of normal saline. Sensory block height was measured by loss of cold sensation to alcohol swabs $10 \mathrm{~min}$ after induction of SA. After ensuring the appropriate level of blockade (T6 - T8), surgery was started. Systolic blood pressure (SBP), diastolic blood pressure (DBP), mean arterial blood pressure (MAP), and heart rate (HR) were monitored and recorded every 2 min until delivery and every $5 \mathrm{~min}$ following thereafter. Episodes of hypotension were considered only in the $30 \mathrm{~min}$ period after spinal anaesthesia induction, to eliminate surgery-related causes for hypotension

All the mothers received $3-4 \mathrm{~L} / \mathrm{min}$ of oxygen by facemask. The above bolus dose was prepared accordingly as $: 10 \mathrm{mg}$ of inj. Ephedrine $=>30 \mathrm{mg}$ diluted to $3 \mathrm{ml}$ NS making a final concentration of $10 \mathrm{mg} / \mathrm{ml}$. . A heart rate $<30 \%$ of baseline is considered as bradycardia and $>30 \%$ of baseline after administration of the bolus dose of prophylactic ephedrine is considered as tachycardia. A SBP $<20 \%$ of baseline is considered as hypotension and $>20 \%$ of baseline after administration of the bolus dose of prophylactic ephedrine is considered as Reactive hypertension. Patients who developed hypotension after bolus dose of prophylactic ephedrine or Normal Saline were given additional rescue boluses of $10 \mathrm{mg}$ ephedrine and IV crystalloid solutions. Hemodynamic changes assessed by another observer who was unaware of the study medication. Frequency of hypotension, reactive hypertension, nausea, vomiting and decrease in Apgar scores at birth, $1 \mathrm{~min}$ and $5 \mathrm{mins}$ were noted.

All the relevant data were recorded on a specialized designed proforma and were analysed by using Microsoft excel 2010, SPSS version 22 software. Mean and SD of age, weight, $\mathrm{Hb}$ gm $\%$, duration of pregnancy, sensory block height, baseline heart rate, systolic blood pressure (SBP), mean arterial pressure (MAP), and rescue bolus doses of inj. Ephedrine IV were calculated. These variables were compared among both the groups. All values for quantitative data was represented as mean+/-SD with statistical significance determined at $p<0.05$. Independent sample t-test is test of significance with $\mathrm{p}<0.05$ as level of significance. Frequency of bradycardia, tachycardia, hypotension, reactive hypertension, nausea, vomiting and decrease in Apgar scores at birth, $1 \mathrm{~min}$ and 5 mins were compared in these two groups. Chi-square test is test of significance with $p<0.05$ as level of 
significance. Discrete/Qualitative data was analysed by using chi- square test.

\section{Results}

A total of 60 parturients were included in the study, 30 each in the two groups. All parturients completed the study. The groups were comparable in age, weight, $\mathrm{Hb} \%$, duration of pregnancy, interval of spinal anesthesia to delivery, interval of spinal anesthesia to end of surgery (Table-1).

There was no significant statistical difference in sensory block height achieved i.e. T6, T7 and T8 $(\mathrm{p}=0.4814) \quad$ (Table-2). There is no significant statistical difference in incidence of bradycardia and tachycardia between the study groups. Bradycardia was least observed in Group 1 $(\mathrm{p}=0.3554)$. Group 1 and 2 showed similar results of incidence of occurrence of tachycardia $(\mathrm{p}=0.2430)($ Table-3).

There was no statistical differences observed between the study groups regarding mean systolic $\mathrm{BP}$ and mean arterial pressure preoperatively, mean systolic BP at 0min after spinal anaesthesia, 20mins, 40mins and 60mins. Incidence of fall from baseline systolic BP at $1 \mathrm{~min}(\mathbf{p}=\mathbf{0 . 0 0 2 2}), 5$ mins $(\mathbf{p}$ $=\mathbf{0 . 0 0 0 1})$ and $20 \mathrm{mins}(\mathbf{p}=\mathbf{0 . 0 0 0 1})$ time intervals was significant in Group 2 patients in comparison to Group 1 (Table-4 / Figure-1).

The incidence of hypotension was $20 \%$ and $46.66 \%$ in Group 1 and 2 respectively. Group 2 patients experienced highest incidence of hypotension. Similar results were found regarding rescue iv ephedrine required to treat further hypotensive episodes (p=0.0500) (Table-5 / Figure-2).

The incidence of reactive hypertension was $23.3 \%$ and $20 \%$ in Group 1 and 2 respectively $(p=0.1037)$ (Table-5 / Figure-2).

Group 2 patients had there first hypotensive episode sooner after spinal anesthesia i.e. at $1 \mathrm{~min}$. Gradually, the incidence of first hypotensive episode was significantly more for Group 2 at 5 and 20mins in comparison to Group $1(\mathbf{p}=\mathbf{0 . 0 2 7 8})$ (Table-6 / Figure-3).

The requirement of total rescue doses of ephedrine was lowest in Groups 1. After receiving prophylactic ephedrine, 24 patients of Group 1 had no hypotensive episode as compared to 16 patients of Group 2.Out of rest 6 patients in Group 1 having hypotension, 1 patient required rescue bolus ephedrine > 10mg.However, 8 patients of Group 2 required $10 \mathrm{mg}$ and rest 6 patients of Group 2 required rescue bolus ephedrine $>10 \mathrm{mg}$ (p=0.0500) (Table-7 / Figure-4).

Mean APGAR score was 9, 10 and 10 respectively at $0 \mathrm{~min}, 1 \mathrm{~min}$ and $5 \mathrm{mins}$ in both the study groups (Figure-5). Both the study groups were found to be statistically similar with respect to Apgar score 0min $(<7), 1 \min (<7)$ and $5 \min (<8)$ (Table-8 $)$. There was no incidence of nausea in Group 1 whereas it was $6.66 \%$ in Group $2(p=0.1503)$ and incidence of vomiting was $6.66 \%$ in Group 1 and $30 \%$ in Group 2. Incidence of vomiting was found significantly higher in Group 2 in comparison to Group 1 (p=0.0195) (Table-8 / Figure-6).

Table 1: Patient Demographics

\begin{tabular}{|l|c|c|c|}
\hline Parameter & $\begin{array}{c}\text { Group-1 } \\
(\mathbf{n = 3 0})\end{array}$ & $\begin{array}{c}\text { Group-2 } \\
(\mathbf{n = 3 0})\end{array}$ & $\begin{array}{c}\text { p- } \\
\text { value }\end{array}$ \\
\hline Age (yrs) & $\begin{array}{c}26.23 \pm \\
4.15\end{array}$ & $\begin{array}{c}25.67 \pm \\
2.893\end{array}$ & 0.2711 \\
\hline Weight (kg) & $\begin{array}{c}58.47 \pm \\
4.981\end{array}$ & $\begin{array}{c}57.03 \pm \\
4.965\end{array}$ & 0.1787 \\
\hline Hb(gm\%) & $\begin{array}{c}10.630 \pm \\
1.046\end{array}$ & $\begin{array}{c}11.210 \pm \\
1.135\end{array}$ & $\mathbf{0 . 0 2 2 1}$ \\
\hline Gestation (days) & $\begin{array}{c}272.50 \pm \\
9.243\end{array}$ & $\begin{array}{c}267.93 \pm \\
8.646\end{array}$ & $\mathbf{0 . 0 2 6 5}$ \\
\hline SA-delivery time (min) & $\begin{array}{c}10.97 \pm \\
2.606\end{array}$ & $\begin{array}{c}11.53 \pm \\
4.840\end{array}$ & 0.7124 \\
\hline $\begin{array}{l}\text { SA-end of surgery } \\
\text { time (min) }\end{array}$ & $\begin{array}{c}37.73 \pm \\
8.729\end{array}$ & $\begin{array}{c}38.07 \pm \\
10.677\end{array}$ & 0.5524 \\
\hline
\end{tabular}

Results are mean \pm SD. SA $=$ Spinal anesthesia

$*$ p-value $<0.05$ is significant 
Table 2: Sensory Block Height

\begin{tabular}{|c|c|c|c|}
\hline $\begin{array}{c}\text { Sensory block } \\
\text { Height }\end{array}$ & $\begin{array}{l}\text { Group-1 } \\
(\mathbf{n}=30)\end{array}$ & $\begin{array}{l}\text { Group-2 } \\
(\mathrm{n}=30)\end{array}$ & $\begin{array}{c}\text { p- } \\
\text { value }\end{array}$ \\
\hline T6 & $23(76.66 \%)$ & $27(90 \%)$ & \multirow{3}{*}{0.4814} \\
\hline T7 & $1(3.33 \%)$ & $1(3.33 \%)$ & \\
\hline T8 & $6(20 \%)$ & $2(6.66 \%)$ & \\
\hline
\end{tabular}

*p-value $<0.05$ is significant

Table-3: Frequency of bradycardia and tachycardia

\begin{tabular}{|c|c|c|c|}
\hline Parameter & $\begin{array}{c}\text { Group-1 } \\
(\mathbf{n = 3 0})\end{array}$ & $\begin{array}{c}\text { Group-2 } \\
(\mathbf{n = 3 0})\end{array}$ & p-value \\
\hline Bradycardia (N\%) & $0(\%)$ & $2(6.66 \%)$ & 0.3554 \\
\hline Tachycardia (N\%) & $7(23.33 \%)$ & $9(30 \%)$ & 0.2430 \\
\hline
\end{tabular}

Table-4: Mean SBP at various intervals

\begin{tabular}{|l|c|c|c|}
\hline $\begin{array}{l}\text { Parameter } \\
(\mathbf{m m H g})\end{array}$ & $\begin{array}{c}\text { Group-1 } \\
(\mathbf{n}=\mathbf{3 0})\end{array}$ & $\begin{array}{c}\text { Group-2 } \\
(\mathbf{n}=\mathbf{3 0})\end{array}$ & p-value \\
\hline Pre OP SBP & $126.97 \pm 15.363$ & $128.07 \pm 14.171$ & 0.6129 \\
\hline Pre OP MAP & $96.53 \pm 12.646$ & $97.17 \pm 13.313$ & 0.5746 \\
\hline SBP after SA & $122.17 \pm 14.774$ & $116.67 \pm 16.771$ & 0.0915 \\
\hline SBP at 1min & $122.00 \pm 14.274$ & $113.17 \pm 13.091$ & $\mathbf{0 . 0 0 2 2}$ \\
\hline SBP at 5mins & $121.37 \pm 17.321$ & $107.13 \pm 14.571$ & $\mathbf{0 . 0 0 0 1}$ \\
\hline SBP at 20mins & $125.70 \pm 13.894$ & $111.90 \pm 11.816$ & $\mathbf{0 . 0 0 0 1}$ \\
\hline SBP at 40mins & $115.43 \pm 10.779$ & $113.30 \pm 9.006$ & 0.2045 \\
\hline SBP at 60mins & $119.90 \pm 7.932$ & $118.87 \pm 13.245$ & 0.3578 \\
\hline
\end{tabular}

Results are mean \pm SD

*p-value $<0.05$ is significant

Fig - 1: Line diagram depicting mean SBP $(\mathrm{mmHg})$ and MAP $(\mathrm{mmHg})$ between study groups

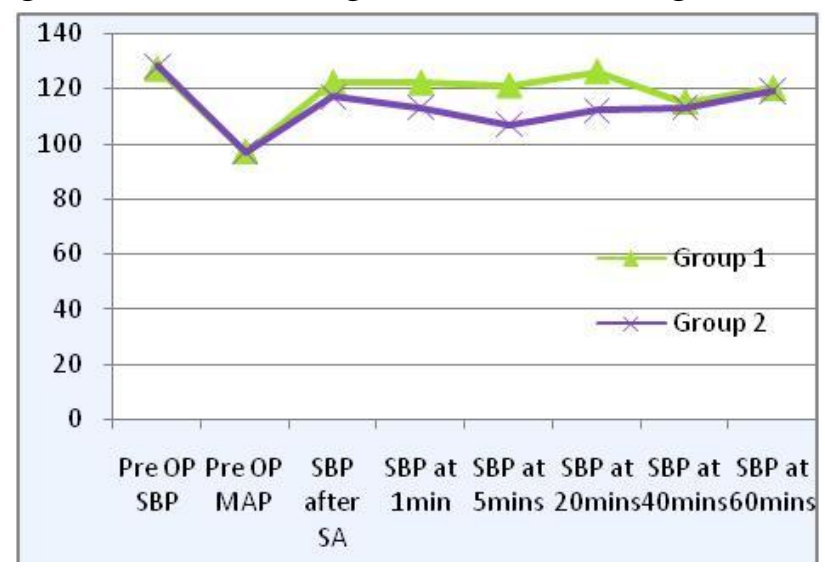

Table - 5: Frequency of hypotension, reactive hypertension and rescue IV Ephedrine

\begin{tabular}{|l|c|c|c|}
\hline Parameter & $\begin{array}{c}\text { Group-1 } \\
(\mathbf{n}=\mathbf{3 0})\end{array}$ & $\begin{array}{c}\text { Group-2 } \\
(\mathbf{n}=\mathbf{3 0})\end{array}$ & p-value \\
\hline $\begin{array}{l}\text { Hypotension } \\
\text { N (\%) }\end{array}$ & $6(20 \%)$ & $\begin{array}{c}14 \\
(46.66 \%)\end{array}$ & $\mathbf{0 . 0 5 0 0}$ \\
\hline $\begin{array}{l}\text { Reactive hypertension } \\
\text { N (\%) }\end{array}$ & $7(23.33 \%)$ & $6(20 \%)$ & 0.1037 \\
\hline $\begin{array}{l}\text { Rescue IV ephedrine } \\
\text { N (\%) }\end{array}$ & $6(20 \%)$ & $\begin{array}{c}14 \\
(46.66 \%)\end{array}$ & $\mathbf{0 . 0 5 0 0}$ \\
\hline
\end{tabular}


Fig -2 : Bar diagram depicting frequency of hypotension and frequency of reactive hypertension in the study groups

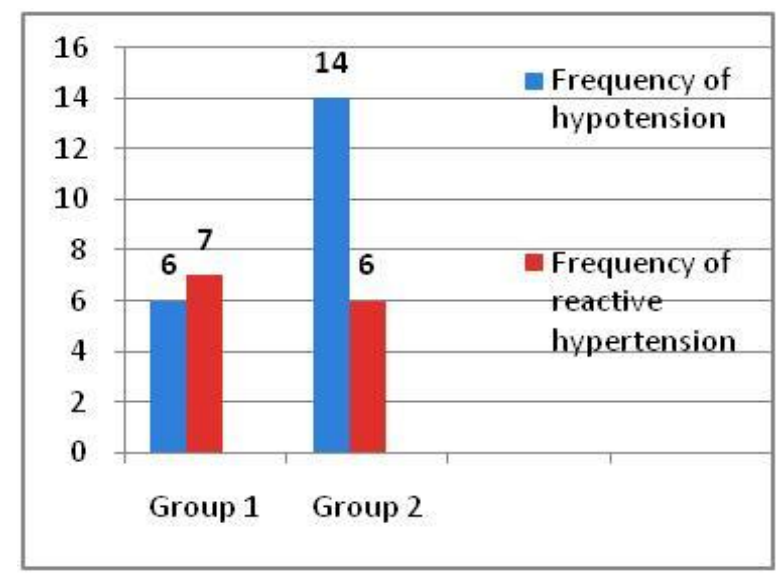

Table - 6: Incidence of first hypotensive episode

\begin{tabular}{|c|c|c|c|}
\hline Time Interval & $\begin{array}{l}\text { Group-1 } \\
(\mathbf{n}=30)\end{array}$ & $\begin{array}{l}\text { Group-2 } \\
(\mathbf{n}=\mathbf{3 0})\end{array}$ & p-value \\
\hline None & 24 & 16 & \multirow{6}{*}{0.0278} \\
\hline $1 \mathrm{~min}$ & 0 & 3 & \\
\hline $5 \operatorname{mins}$ & 1 & 6 & \\
\hline 20mins & 2 & 5 & \\
\hline 40mins & 3 & 0 & \\
\hline 60mins & 0 & 0 & \\
\hline
\end{tabular}

${ }^{*} \mathrm{p}$-value $<0.05$ is significant

Fig -3: Bar diagram depicting incidence of first hypotensive episode

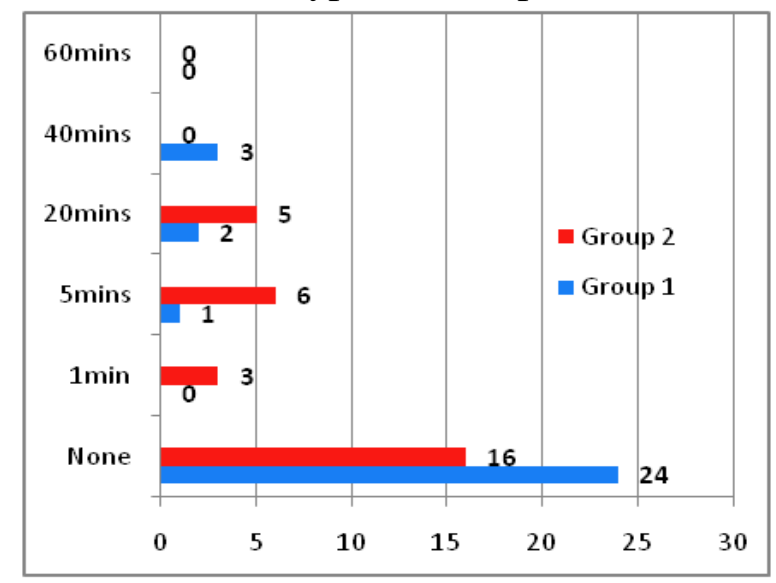

Table 7 : Rescue ephedrine given to treat hypotension

\begin{tabular}{|c|c|c|c|}
\hline $\begin{array}{c}\text { Total ephedrine } \\
\text { use (mg) }\end{array}$ & $\begin{array}{l}\text { Group-1 } \\
(\mathrm{n}=30)\end{array}$ & $\begin{array}{l}\text { Group-2 } \\
(\mathrm{n}=30)\end{array}$ & p-value \\
\hline No & 24 & 16 & \multirow{5}{*}{0.0500} \\
\hline 10 & 5 & 8 & \\
\hline 20 & 0 & 5 & \\
\hline 30 & 1 & 0 & \\
\hline 40 & 0 & 1 & \\
\hline
\end{tabular}

${ }^{*}$ p-value $<0.05$ is significant 
Fig-4: Bar diagram depicting Rescue ephedrine given to treat hypotension

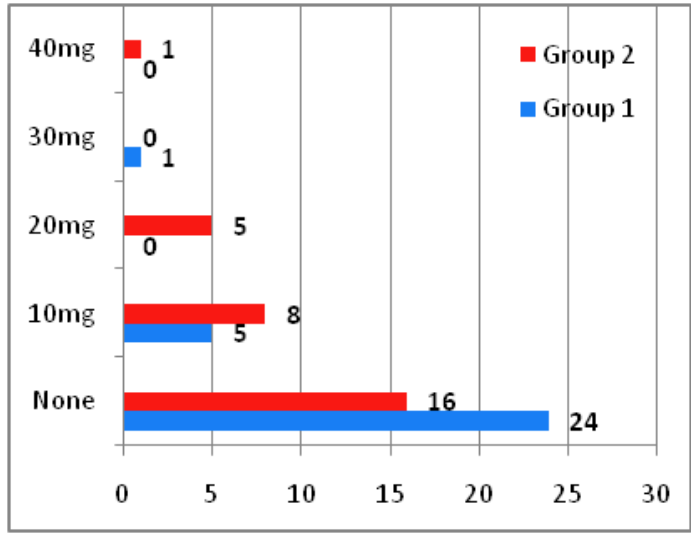

Table -8: Side effects and neonatal outcome

\begin{tabular}{|c|c|c|c|}
\hline Parameter & $\begin{array}{l}\text { Group-1 } \\
(\mathrm{n}=30)\end{array}$ & $\begin{array}{l}\text { Group-2 } \\
(\mathrm{n}=30)\end{array}$ & $\begin{array}{l}\text { p- } \\
\text { value }\end{array}$ \\
\hline Nausea & $0(0 \%)$ & $2(6.66 \%)$ & 0.1503 \\
\hline Vomiting & $2(6.66 \%)$ & $9(30 \%)$ & 0.0195 \\
\hline $\begin{array}{llll}\begin{array}{l}\text { Apgar } \\
(<7)\end{array} & \text { score } 0 \text { min } \\
\end{array}$ & $2(6.66 \%)$ & $2(6.66 \%)$ & 1.000 \\
\hline $\begin{array}{l}\text { Apgar score } 1 \text { min } \\
(<7)\end{array}$ & $0(0 \%)$ & $0(0 \%)$ & - \\
\hline $\begin{array}{llll}\begin{array}{l}\text { Apgar } \\
(<8)\end{array} & \text { score } 5 & \text { min } \\
\end{array}$ & $0(0 \%)$ & $0(0 \%)$ & - \\
\hline
\end{tabular}

$*$ p-value $<0.05$ is significant

Fig-5: Bar diagram depicting the mean APGAR scores

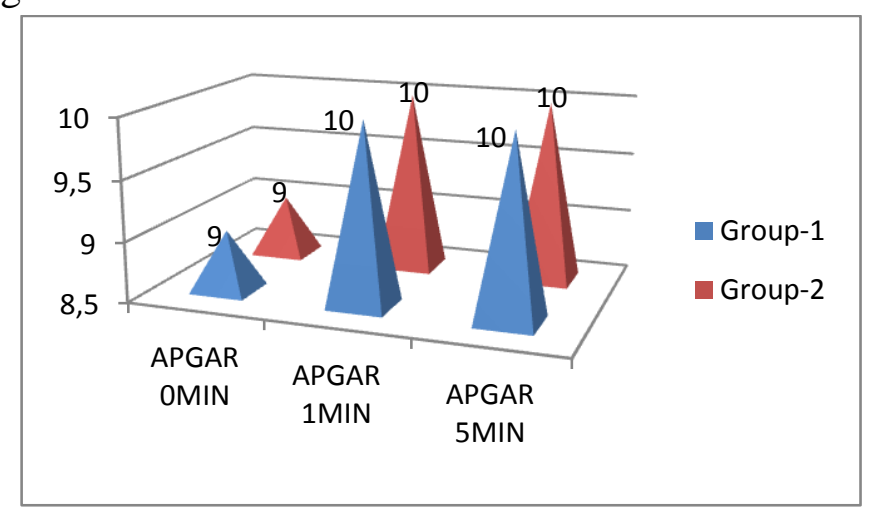

Fig-6 : Bar diagram depicting incidence of nausea and vomiting in \%

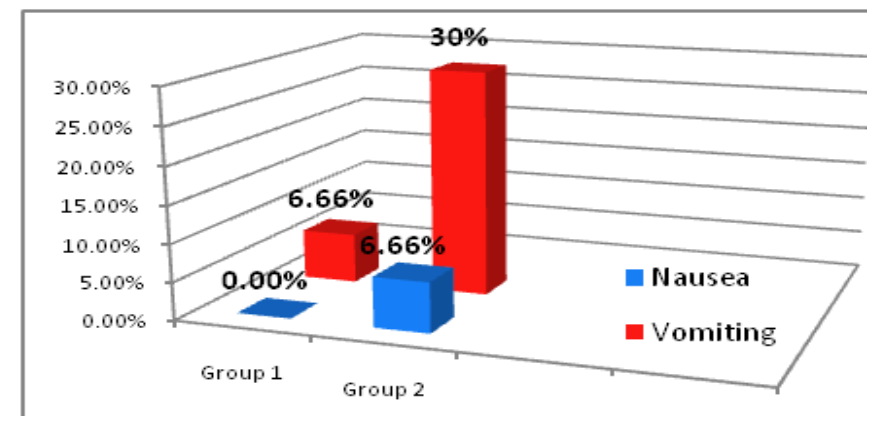




\section{Discussion}

Hypotension is the most common serious adverse effect of spinal anaesthesia for cesarean delivery, with an incidence reported in the literature up to $80 \%$. It is defined as decrease in systolic BP below $20 \%$ from the baseline value. ${ }^{[2]}$

Various strategies for preventing hypotension have been investigated and tried as it may have detrimental maternal and neonatal effects. Many interventions such as pelvic tilt, leg elevation and wrapping, and the prophylactic administration of fluids or vasopressors have been proposed and used to reduce the incidence of maternal hypotension. Despite all these measures, approximately $25 \%$ of patients still experience hypotensive episodes. ${ }^{[2]}$

Ephedrine is not a potent arterial vasoconstrictor; it maintains BP mainly by increasing myocardial contractility, cardiac output and heart rate. This may be the reason that high doses of prophylactic intravenous ephedrine are associated with side effects such as tachycardia and reactive hypertension, which is usually considered as systolic BP > 140mmHg. ${ }^{[2]}$

In our study, there was insignificant variations in the age, weight, $\mathrm{Hb} \%$ and gestational age of the parturients between the groups which emphasize the fact that this study was made blind on the above parameters. In other words, parturients considered for our study who received ephedrine $10 \mathrm{mg}$ or an equal volume of normal saline were comparable as regard to their age, weight, $\mathrm{Hb} \%$ and gestational age.

There was no significant statistical difference in incidence of bradycardia ( $p=0.3554)$ and tachycardia $(\mathrm{p}=0.2430)$ between the study groups. Bradycardia was least observed in Group 1. Group 1 and 2 showed similar results of incidence of occurrence of tachycardia. Other studies found supporting our study are :Kee, Warwick D. Ngan et al ${ }^{[10]}$ noticed heart rate changes were similar among groups i.e. ephedrine $10,20,30 \mathrm{mg}$ iv and saline control group. They observed heart rate changes with an increased trend for around 10mins. This change was attributed to causes such as anxiety, aortocaval compression, and hypotension. Lawrence CTsen et $a l^{[4]}$ found significant changes in baseline heart rate were observed in ephedrine 10mg and control $2 \mathrm{ml}$ normal saline after spinal anesthesia. Iqra $\underline{\text { Nazir }}$ et $a l^{[11]}$ recorded the incidence of bradycardia to be lower in ephedrine group $10 \mathrm{mg}$ iv with rescue bolus of $5 \mathrm{mg}$ as compared to phenylephrine group $100 \mathrm{mcg}$ iv with rescue bolus of $50 \mathrm{mcg}$.

In present study, there was no statistical differences observed between the study groups regarding mean systolic $\mathrm{BP}(\mathrm{p}=0.6129)$ and mean arterial pressure $(\mathrm{p}=0.5746)$ preoperatively, mean systolic BP at 0 min after spinal anaesthesia $(\mathrm{p}=0.0915), 40 \mathrm{mins}(\mathrm{p}=$ $0.2045)$ and $60 \mathrm{mins}(\mathrm{p}=0.3578)$. Incidence of fall from baseline systolic BP at $1 \mathrm{~min}(\mathbf{p}=$ $\mathbf{0 . 0 0 2 2}), 5 \mathrm{mins}(\mathbf{p}=\mathbf{0 . 0 0 0 1})$ and $20 \mathrm{mins}(\mathbf{p}=$ 0.0001) time intervals is significant in Group 2 patients in comparison to Group 1. The incidence of fall in BP was maximum during the first 120mins (till time of delivery) following subarachnoid block and we observed that vasopressor used was maximum in this period. This corresponds to the immediate sympathetic block after intrathecal injection. Lawrence CTsen et $a l^{[4]}$ found significant changes from baseline in MAP and systemic vascular resistance index in ephedrine $10 \mathrm{mg}$ and control $2 \mathrm{ml}$ normal saline after spinal anaesthesia.

In our study, 20 patients out of 60 were recorded to have intra-operative blood pressure below $20 \%$ of the base-line value at one instance. The total incidence of hypotension was $33.3 \%$. The incidences of hypotension in our study are $20 \%$ and $46.66 \%$ in the ephedrine group (Group 1) and control group (Group 2), respectively ( $\mathbf{p}=\mathbf{0 . 0 5 0 0}$ ). Similar results were found in other studies. Lawrence CTsen et al ${ }^{[4]}$ observed the incidence of hypotension was $70 \%$ in both ephedrine $12 \mathrm{mg}$ and normal saline groups. In the study by Simon et al. [5] , the incidence of hypotension was $63.8 \%$ in those patients receiving $10 \mathrm{mg}$ prophylactic intravenous ephedrine in comparison to higher 
doses of either 15 or $20 \mathrm{mg}$ ephedrine $(p<0.05)$. Similarly, Vercauteren, Marcel P. et $a l^{[6]}$ found more patients in the control group to develop hypotension (58\% vs $25 \%, p<0.05)$. $J$. P. R. Loughrey et $a l^{[7]}$ also found significantly higher incidence of hypotension in control group (60\%) compared to ephedrine $12 \mathrm{mg}$ group (27\%), but not in ephedrine $6 \mathrm{mg}$ group $(50 \%)$ ( $\mathrm{p}<0.05)$. Takhelmayum Hemjit Singh et al ${ }^{[2]}$ showed the incidences of hypotension to be $60 \%$ and $72 \%$ in the ephedrine $5 \mathrm{mg}$ and control group i.e. equal volume normal saline, respectively $(p>0.05)$. In a study by Muhammad Shakeel Iqbal et al ${ }^{[1]}$, the incidence of hypotension was significantly higher in Group-I parturients receiving a 10mg prophylactic dose of ephedrine than in Group-II and Group-III parturients receiving $15 \mathrm{mg}$ or $20 \mathrm{mg}$ of ephedrine respectively (53.3\% vs. $13.3 \%$ and $3.3 \%$ respectively). Kenan Kaygusuz et al ${ }^{[8]}$ found significantly lower incidences of hypotension in the ephedrine $0.5 \mathrm{mg} / \mathrm{kg}$ group compared with the control group (8 [38.1\%] vs. 18 [85.7\%]) ( $\mathrm{p}<$ 0.05 ). Ngan Kee et al. ${ }^{[10]}$ recorded 35\%, 95\%, $85 \%$, and $80 \%$ incidences of hypotension with $30 \mathrm{mg}$ ephedrine, saline control, $20 \mathrm{mg}$ and $10 \mathrm{mg}$ bolus ephedrine respectively ( $\mathrm{p}<0.0001)$.

In our study, the average vasopressor (rescue bolus ephedrine $10 \mathrm{mg}$ iv ) consumption in our study was reduced in the ephedrine Group 1 as compared to control Group 2, which was statistically significant $(\mathbf{p}=\mathbf{0 . 0 5 0 0})$, and this may be due to the effect of bolus ephedrine in the study group. After receiving prophylactic ephedrine, 24 patients of Group 1 had no hypotensive episode as compared to 16 patients of Group 2 receiving equal volume of normal saline. Out of rest 6 patients in Group 1 having hypotension, only 1 patient required rescue bolus ephedrine $>10 \mathrm{mg}$. However, 8 patients of Group 2 required $10 \mathrm{mg}$ and rest 6 patients of Group 2 required rescue bolus ephedrine $>10 \mathrm{mg}$. The incidence of fall in BP was maximum during the first 1-20mins (till time of delivery) following subarachnoid block and we observed that vasopressor used was maximum in this period. This corresponds to the immediate sympathetic block after intrathecal injection. Ngan Kee et al. ${ }^{[10]}$ also opined that vasopressor requirements were reduced till the time of delivery only and the average median dose was 0 versus $10 \mathrm{mg}$ of ephedrine $(\mathrm{p}<0.001)$ in their study using vasopressor infusion. J. P. R. Loughrey et $a l^{[7]}$ found fewer rescue boluses of ephedrine were required in ephedrine $12 \mathrm{mg}$ iv compared with normal saline control group (1.8 \pm 1.2 vs. $3.3 \pm 2.1, \mathrm{P}<0.05$ ).

Group 2 patients had there first hypotensive episode sooner after spinal anaesthesia i.e. at $1 \mathrm{~min}$ and required rescue bolus ephedrine simultaneously sooner. Gradually, the incidence of first hypotensive episode was significantly more for Group 2 at 5 and 20mins in comparison to Group 1 ( $\mathbf{p = 0 . 0 2 7 8 )}$.

The incidence of reactive hypertension was $23.3 \%$ and $20 \%$ in Group-1 and 2 respectively $(\mathrm{p}=0.1037)$. Kee, Warwick D. Ngan et al ${ }^{[10]}$ observed reactive hypertension in 9 patients $(45 \%)$ in the $30 \mathrm{mg}$ group ( mean highest SAP $120 \%$ of baseline, range $104 \%-143 \%$ ) compared with $2(10 \%)$ in control group, $1(5 \%)$ in ephedrine $10 \mathrm{mg}$ iv group, and $5(25 \%)$ in ephedrine 20mg iv group ( $\mathrm{p}=0.009$ ).

Neonatal outcome as evidenced by Apgar score was almost similar in both the groups in our study. Mean APGAR score was 9, 9 and 10 respectively at $0 \mathrm{~min}, 1 \mathrm{~min}$ and $5 \mathrm{mins}$ respectively in both the study groups. Prakash $S$ et al ${ }^{[9]}$, Kenan Kaygusuz et $a l^{[8]}$ and Ngan Kee et $a l^{[10]}$ also found similar results. However, in the study conducted in a dose range of 10-30 mg by Ngan Kee et al. ${ }^{[10]}$, the potential vasoconstrictive effects of ephedrine may have less detrimental effect on uteroplacental blood flow than the effects of hypotension. Furthermore, our study showed improved neonatal outcome in a way that only 4 neonate had APGAR score below 7 at birth and none had APGAR score below 7 at 1 and 5 mins.

In present study, the incidence of side effect -2 out of 60 patients developed nausea $(\mathrm{p}=0.1503)$ and 11 out of 60 patients developed vomiting ( $\mathbf{p = 0 . 0 1 9 5 )}$ making the incidence $21.66 \%$, but its 
correlation with respect to frequency of hypotension and other hemodynamic parameters could not be related. Similar results were found in other studies. J. P. R. Loughrey et al ${ }^{[7]}$ found no significant differences in the incidence of maternal nausea or vomiting between ephedrine $12 \mathrm{mg}$ iv and normal saline control group. Similarly, Kenan Kaygusuz et $a l^{[8]}$ observed significant lower incidences of nausea and vomiting in the ephedrine group compared with the control group (4 [19\%] vs. 12 [57.1\%], respectively) ( $\mathrm{p}<0.05)$. Kee, Warwick D. Ngan et $a l^{[10]}$ found incidence of nausea and vomiting were similar among groups and concluded that the smallest effective dose of ephedrine to reduce the incidence of hypotension was 30mg. However, this dose did not completely eliminate nausea and vomiting.

Our study was not without any limitations. Hypotension due to blood loss and experience of the operating surgeon in controlling bleeding might be a confounding factor. Left lateral tilt by keeping a wedge done to all the parturients undergoing cesarean delivery might also be a confounding factor. Block height was not equal in all the patients, and further study is required to determine the exact dose response.

\section{Conclusion}

We found from our study that prophylactic use of intravenous ephedrine $10 \mathrm{mg}$ bolus significantly decrease the incidence of maternal hypotension than the control group. $10 \mathrm{mg}$ of IV Ephedrine brings a better hemodynamic stability with less incidence of various side effects like reactive hypertension, nausea and vomiting in the mother as well as does not have adverse neonatal outcome which is evidenced by APGAR score at birth, $1 \mathrm{~min}$ and $5 \mathrm{mins}$ following delivery.

\section{Conflicts of Interest: Nil}

\section{References}

1. Iqbal MS, Ishaq M, Masood A, Khan MZ. Optimal dose of prophylactic intravenous ephedrine for spinal induced hypotension during cesarean section. Anaesth Pain Intensive Care 2010;14:71- 5.

2. Singh, et al.: Prophylactic intravenous ephedrine for prevention of hypotension. Journal of Medical Society / May-Aug 2016 / Vol 30 | Issue 2. DOI: 10.4103/09724958.182922

3. Haleh Ghaem et al. Maternal and anesthesia related risk factors and incidence of spinal anaesthesia- induced hypotension in elective caesarean section: A multinomial logistic regression. Indian Journal of Anesthesia 2018. Volume 62. Issue 1. January 2018.

4. Lawrence CTsen et al. Hemodynamic effects of simultaneous administration of intravenous ephedrine and spinal anesthesia for cesarean delivery. Journal of Clinical Anesthesia.Volume 12, Issue 5, August 2000, Pages 378-382.

5. Simon L, Provenchère $S$, de Saint Blanquat L, Boulay G, Hamza J. Dose of prophylactic intravenous ephedrine during spinal anesthesia for cesarean section. J Clin Anesth 2001;13:366- 9.

6. Vercauteren MP, Coppejans HC, Hoffmann VH, Mertens E, Adriaensen HA. Prevention of hypotension by a single 5-mg dose of ephedrine during small dose spinal anesthesia in prehydrated cesarean delivery patients. Anesth Analg 2000; 90: 324-7.

7. Loughrey JPR, Walsh F, Gardiner J. Prophylactic intravenous bolus ephedrine for elective Caesarean section under spinal anesthesia . Eur J Anaesthesiol 2002; 19: 63-8.

8. Kenan Kaygusuz, Sinan Gursoy, Ali Cetin, Zeki Kahramanoglu, Fikret Ozkan. The Effects of Intravenous Ephedrine During Spinal Anesthesia for Cesarean Delivery: A Randomized Controlled Trial. J Korean Med Sci. 2009 Oct; 24(5): 883-888.

9. Prakash S, Pramanik V, Chellani H, Salhan S, Gogia AR. Maternal and neonatal effects of bolus administration of ephedrine and phenylephrine during spinal anaesthesia for 
caesarean delivery: a randomised study. Int J Obstet Anesth. 2010Jan;19(1):24-30.

doi: 10.1016/j.ijoa.2009.02.007. Epub 2009 Aug 7.

10. Ngan Kee WD, Khaw KS, Lee BB, et al. A dose-response study of prophylactic intravenous ephedrine for the prevention of hypotension during spinal anesthesia for Cesarean delivery. Anesth Analg 2000; 90: 1390-5.

11. Iqra Nazir, Mubasher A Bhat, Syed Qazi, Velayat N Buchh, Showkat A Gurcoo. Comparison between phenylephrine and ephedrine in preventing hypotension during spinal anesthesia for cesarean section. J Obstet Anaesth Crit Care [serial online] 2012 [cited 2019 Nov 26];2:92-7. 